\title{
Client satisfaction of hand therapy intervention: An evaluation of the effectiveness of therapy for clients recovered from complex regional pain syndrome
}

\author{
Nirmeen Zagzoog MSc (OT) candidate ${ }^{1}$, Shrikant J Chinchalkar BSc OT OT Reg (Ont) OTR CHT $^{2}$, \\ Thelma Sumsion PhD OT Reg (Ont) ${ }^{1}$
}

\begin{abstract}
N Zagzoog, SJ Chinchalkar, T Sumsion. Client satisfaction of hand therapy intervention: An evaluation of the effectiveness of therapy for clients recovered from complex regional pain syndrome. Can J Plast Surg 2008;16(1):27-35.

Complex regional pain syndrome (CRPS) is a neuropathic pain condition that may develop following trauma to an extremity. Clients treated for CRPS at St Joseph's Health Care London - Hand and Upper Limb Centre, London, Ontario, were asked to evaluate their level of satisfaction with the treatment they had received by comparing their pain, functional status and emotional status before and after receiving therapy. The results indicated a high level of satisfaction among clients, attributable to the unique nature of the therapy program in use at this facility, where the occupational therapist works in close collaboration with the surgeon and pain specialists, and the therapy regimen is designed for each client individually according to his or her needs. The unique contribution of the present study to the body of clinical literature on CRPS is that it introduces a focus on client functionality and on client satisfaction with therapy received.
\end{abstract}

Key Words: Complex regional pain syndrome; Outcome measure; Patient satisfaction; Reflex sympathetic dystrophy
La satisfaction des clients envers une intervention thérapeutique de la main : Une évaluation de l'efficacité de la thérapie chez les clients remis d'un syndrome algodystrophique

\begin{abstract}
Le syndrome algodystrophique est une douleur neuropathique qui peut se manifester après le traumatisme d'une extrémité. Les clients traités pour un syndrome algodystrophique au St. Joseph's Health Care London - Hand and Upper Limb Centre de London, en Ontario, ont été invités à évaluer leur taux de satisfaction envers le traitement qu'ils avaient reçu en comparant leur douleur, leurs capacités fonctionnelles et leur état émotif avant et après la thérapie. Les résultats faisaient état d'un fort degré de satisfaction chez les clients, attribuable à la nature unique du programme thérapeutique utilisé dans cet établissement, où un ergothérapeute travaille en étroite collaboration avec le chirurgien et les spécialistes de la douleur et où le schéma thérapeutique est adapté à chaque client, d'après ses besoins. L'apport unique de la présente étude à l'ensemble des publications cliniques sur le syndrome algodystrophique vient du fait qu'elle s'attarde à la fonctionnalité du client et à sa satisfaction à l'égard de la thérapie qu'il a reçue.
\end{abstract}

R eflex sympathetic dystrophy (RSD), recently renamed R.omplex regional pain syndrome (CRPS), is a neuropathic pain syndrome that may develop as a result of upper extremity injury (1). The new term was proposed by the International Association for the Study of Pain to provide a more descriptive designation based on the clinical features, location and specifics of the injury, without presuming pathophysiological mechanisms as the cause of the disorder, because sympathetic hyperactivity may not necessarily be the cause of the pain in every case (1).

The condition is characterized by spontaneous, severe regional pain and marked physiological changes following a noxious event (2). The pain, usually in the distal part of a limb, is disproportionate to the extent or severity of the inciting injury, and is associated with autonomic and sensory symptoms, including skin discolouration or temperature changes, sweating or edema, and motor dysfunction of the affected limb (3). However, the pain has also been noted, in some cases, to spread proximally, and can involve the entire limb (4). Painful response to exposure to cold is a hallmark of neuropathic pain; thus, it is frequently experienced by clients with CRPS (5). The diagnosis of CRPS relies on clinical findings and is excluded by other existing conditions that may be the source of the pain and account for the degree of dysfunction (2). CRPS type I occurs without a definable nerve lesion (formerly RSD), type II occurs with a definable nerve lesion (formerly causalgia) and type III refers to a group not otherwise specified clients who do not fulfill the criteria for either type I or type II (1). Type I CRPS, the most common, is estimated to occur after $7 \%$ or more of Colles' fractures, $1 \%$ to $2 \%$ of other fractures and $2 \%$ to $5 \%$ of minor peripheral nerve injuries (6). It may also occur after stroke, vascular disease, infection or myocardial infarction (7). No identifiable precipitant is found in up to $25 \%$ of cases (6). Epidemiologically, among smokers, women are more prone to develop CRPS than men $(5,8)$. Individuals with CRPS tend to report the same pain intensity and the same levels of psychological distress as those with back pain or local neuropathy (9). They also report limitations in carrying out the activities of their normal daily life and in the pursuit of their occupation $(10,11)$. In addition, they have

${ }^{1}$ School of Occupational Therapy, The University of Western Ontario; ${ }^{2}$ St Joseph's Health Care London - Hand and Upper Limb Centre, London, Ontario

Correspondence and reprints: Shrikant J Chinchalkar, Hand Therapy Division/Hand and Upper Limb Centre, St Joseph's Health Care London, 268 Grosvenor Street, London, Ontario N6A 4L6. Telephone 519-646-6001 ext 64807, fax 519- 646-6317,

e-mail Shrikant.Chinchalkar@sjhc.london.on.ca 
difficulty functioning in society and fulfilling social roles $(12,13)$. Clients with CRPS, especially in its later stages, are prone to develop psychological symptoms, including depression, irritability, withdrawal behaviour and feelings of hopelessness (14). Several psychological interventions have been suggested as adjunctive treatments in CRPS management, including various forms of relaxation training, biofeedback and cognitive behavioural therapy $(15-17)$. Chronic pain due to CRPS has been found to have a profound impact on many aspects of the lives of both clients and their immediate families (18).

There is little consensus on how CRPS should be managed; however, most authorities agree that treatment should involve both pharmacological and nonpharmacological interventions (19). The main goal of the pharmacological treatment is pain relief, which permits the institution of the rehabilitation program (2). Conversely, functional restoration is the primary goal of all therapeutic interventions, with specific, individually tailored exercise therapy being crucial to re-establishing functionality (20). Early diagnosis and prompt intervention are the most important factors in the successful treatment of CRPS (19).

A review of the literature did not yield any studies that examined the level of client satisfaction or evaluated functional outcomes for a given therapy. While the literature presents the multitude of symptoms observed in these clients and considers possible treatment options, it does not go any further than this. However, in a recent paper, Zyluk (20) retrospectively analysed 94 patients with RSD of the hand who were treated successfully. He concluded that "in spite of resolution of the acute RSD problem, significant long term sequelae of RSD continued to impair function of the hand in a proportion of patients". Studies have shown that type I CRPS entails impairments, activity limitations and participation problems as described in the International Classification of Functioning (2123). Another recent study (24) involving 30 individuals with nonacute upper limb type I CRPS was conducted to determine the degree of impairment and activity limitations, as well as their inter-relationship. It was found that all subjects were still impaired to some degree nearly three years after the precipitating event. The upper limb involved was less active than its counterpart, with impaired active range of motion and reduced grip strength being the most important factors in activity limiations (24).

Hand therapy is an important part of the management of CRPS affecting the upper extremities. It is common practice for occupational therapists to be involved in the treatment of clients diagnosed with CRPS. The occupational therapist's goal is to improve hand function through various treatment modalities and to facilitate re-engagement in 'safe' occupations. Special vocational rehabilitation training is usually started in the later stages of the therapy program, including progressive stress loading and work hardening (20). Although the goal of the occupational therapist is always to ensure the client's satisfaction with any given therapy based on the client's functional outcomes, the existing literature fails to address the issue of how satisfied clients diagnosed with CRPS were with the hand therapy that they received. In a published case study, researchers reported on the most effective treatment for type I CRPS with a series of nerve blocks followed immediately by occupational therapy, but their investigation failed to evaluate the clients' personal satisfaction (25).

The therapist is most likely to be the first person to recognize and identify early onset of CRPS; therefore, it is important for him or her to have a good understanding of the dynamic signs and symptoms of CRPS. There is no set recipe for treating individuals with CRPS. Thus, for a treatment program to be effective in any given case, there needs to be ongoing observation, assessment of the client's response to previous treatments, and assessment of the client's levels of pain and irritability accompanied by sound clinical reasoning (26). In the absence of a widely accepted, broadly efficacious medical treatment, clinical experts have emphasized the importance of a multidisciplinary approach in the management of CRPS (27). In keeping with this, the hand therapy provided at our facility adopts the multidisciplinary approach and emphasizes level of pain experienced and its effect on functionality in managing CRPS. Hand therapists never work in isolation from other health care professionals involved in treating clients with CRPS. It is quite common for clients facing emotional challenges to be referred for psychological consultation when appropriate.

The purpose of the present investigation was to survey a sample of our clients with CRPS to evaluate their level of satisfaction with the hand therapy that they had received in terms of pain control and optimal restoration of hand functionality. It was hypothesized that clients who had gone through a period of therapy including massage, thermoregulation, joint mobilization, desensitization, range of motion exercises, fluidotherapy, electrical nerve stimulation, ultrasound, splinting and/or continuous passive motion, in combination with proper education and pain control, would have an exceptionally good functional outcome and therefore experience a high level of satisfaction with the treatment they received.

\section{Patient selection}

\section{PATIENTS AND METHODS}

Participants for the present study were individuals who had been diagnosed with CRPS and undergone a hand therapy program. The last 60 consecutive clients between 1997 and 2004 who had experienced CRPS in their upper extremities were selected from the client list. To meet the inclusion criteria, participants had to have been diagnosed with (according to the diagnostic criteria of the International Association for the Study of Pain) and functionally recovered from CRPS. The 60 prospective participants received the survey questionnaire through the mail. Four $(6 \%)$ of the questionnaires were returned as undeliverable, and 32 (53\%) questionnaires were mailed back by the prospective participants. Of these 32 questionnaires, 29 were returned completed; three were returned blank. One questionnaire had to be excluded because it was incomplete. Thus, a total of 28 questionnaires were used in the present study. Using Dillman's method (28), a response rate of $53.84 \%$ was achieved.

The mail survey was selected as the means of gathering data because it is an efficient way to target a large sample size distributed over a large geographic area. It has the added advantage of being practicable in cases in which names and addresses are known, but telephone numbers are not available. The questionnaire in the present study also included a diagram, something that it is not possible to use in a telephone interview. The mail survey was also chosen for its relative lack of intrusiveness in comparison with other forms of information gathering, because it allows participants to respond at their leisure, rather than at the sometimes inconvenient moment when they are contacted for a telephone or personal interview. 
The questionnaire format is easy to analyze, and the data gathered in this way can easily be entered into and tabulated by a variety of computer programs. A final reason for choosing the mail survey was that it reduces bias by eliminating verbal or visual cues that may influence the respondent to give answers confirming the researcher's opinions $(28,29)$.

\section{Study design and procedures}

The study was designed to include a self-evaluation of the client's status before and after receiving therapy. The evaluation was conducted by means of a self-administered client satisfaction test aimed at gauging, both quantitatively and qualitatively, the clients' satisfaction with the hand therapy that they had received. The survey questions were formulated based on a review of CRPS literature and were drawn from several standardized, previously validated instruments (Patient Rated Wrist Evaluation [30,31], SF-36 Health Survey [32], and Disabilities of the Arm, Shoulder and Hand Outcome Measure $[33,34])$, as well as other widely accepted adaptive instruments and measures. The questionnaire was further refined after it was pilot tested on three clients for design and face validity. The questionnaire included a combination of Likert scales, multiple-choice questions, fill-in-the-blank statements, dichotomous format and an additional-comments section. The questions addressed the following areas: client demographics, employment status, functional status, pain severity and frequency, emotional status, treatments received and overall satisfaction with therapy.

The questionnaire, along with a letter inviting the clients to participate in the study and a self-addressed stamped envelope, was mailed out to the prospective participants. The questionnaires were number coded to preserve anonymity and protect client privacy. A follow-up reminder letter was sent to the potential respondents after six weeks of initial mailing.

\section{Data management}

The data collected from the survey were entered into the Statistical Package for the Social Sciences Version 11 (SPSS Inc, USA) (35). Each question was set as a separate variable. Frequencies were compiled for each variable and then reviewed to ensure that no additional response categories, indicating errors, were present. Whenever an error was found under a given variable, the variable was reviewed for mistakes. The identification number for the row in which the error was found was then used to retrieve the hard copy of the designated questionnaire to correct the response.

With respect to missing responses, $7 \%$ of responses were missing for questions 23 and $23 \mathrm{~b}$, while $18 \%$ of responses were missing for question 21c. Only one missing response was found for questions 9, 12, 14, 17, 18 and 22 (pain severity, regular activities, and emotional disturbances with social activities; all pre- and post-treatment). Two participants did not respond to questions 10 and 19 (pain frequency pre- and post-treatment). Less than $11 \%$ of the questionnaires were missing a response for questions 13 and 20 (emotional disturbances pre- and posttreatment), and approximately 33\% were missing a response for question 21 (comparison of emotional disturbances posttreatment to pretreatment).

\section{Data analysis}

The data relating to demographics, employment status, hand dominance, types of injury, time of diagnosis and therapy received were summarized in the form of frequencies. The data analysis involved a comparison of pre- and post-therapy findings in the form of the mean \pm SD. The data were analyzed on the basis of individual questions, as well as groupings of questions in each section. Both quantitative and qualitative responses were recorded for each participant. The scale ratings obtained on the survey were treated as interval or categorical on all analyses. Parametric dependent $t$ tests were used to compare the differences between the means of the pre- and posttherapy results for each pair of two related variables, and to evaluate that difference for the 0.05 alpha level of significance (36).

\section{Participant demographics}

\section{RESULTS}

A majority of the participants $(78.60 \%)$ were women $(21.40 \%$ men). Participants were between the ages of 40 and 80 years (mean \pm SD age $59.03 \pm 12.49$ years). The majority of participants were right handed $(89.30 \% ; 10.70 \%$ were left handed), and $64.30 \%$ of the respondents reported CRPS in their dominant hand. In addition, almost all participants (93\%) indicated that they had experienced CRPS as a result of an injury to the affected hand, with $75 \%$ of these injuries being fractures and $25 \%$ being soft tissue trauma and nerve injury. A majority (64.30\%) indicated that they had been diagnosed with CRPS early following the precipitating event. Because there is no general consensus in the literature on a specific timeframe for the diagnosis to be considered 'early', in the present study, the diagnosis was deemed to be relatively early if it was made within three to six weeks following the initial hand injury or precipitating event.

\section{Employment status}

Approximately $35 \%$ of the participants were retired. However, $40 \%$ of those not past retirement age indicated that they were unable to work because of impaired hand functionality resulting from CRPS, while 25\% indicated that they were employed in some capacity. Of those who were employed, 64\% reported that they had not had to change their job because of their hand condition. Clients were asked to report whether their ability to work had been affected by their hand condition in three categories: not at all, working fewer hours and working modified duties. Only 18\% of those who responded to this question indicated that their ability to work had generally not been affected by CRPS, while $21.40 \%$ indicated that their hand condition had resulted in modified work duties.

\section{Pain severity and frequency}

Participants were asked to mark, on an upper-limb diagram, the site where they had experienced the pain before beginning treatment. Fifteen participants $(53.57 \%)$ had had a localized pain spot in relation to their initial injury, whereas 13 participants $(46.42 \%)$ had experienced radiated pain over the affected limb in relation to the initial site of the injury.

Participants were asked to rate the severity of their pain before and after therapy for five conditions on an 11-point box scale from 0 (none) to 10 (worst). The five conditions included pain at rest, pain when lifting heavy objects, pain when doing repeated wrist-hand movement activities, pain at night and pain at its worst. Mean scores for the five conditions before and after therapy were calculated and compared. Similarly, participants were also asked to rate the frequency of their pain before 


\section{TABLE 1}

Functional status, pain severity and frequency, and emotional status ratings pre- and post-therapy

\begin{tabular}{|c|c|c|c|c|c|}
\hline & $\mathbf{n}$ & $\begin{array}{l}\text { Pretherapy } \\
\text { scores }^{*}\end{array}$ & $\begin{array}{l}\text { Post-therapy } \\
\text { scores }^{*}\end{array}$ & $\begin{array}{l}\text { Change } \\
\text { scores }^{*}\end{array}$ & $t \quad$ df \\
\hline $\begin{array}{l}\text { Combined specific } \\
\text { activities }\end{array}$ & 28 & $9.46 \pm 0.91$ & $5.14 \pm 3.20$ & $4.31 \pm 3.48$ & $6.54^{\dagger} 27$ \\
\hline $\begin{array}{l}\text { Combined regular } \\
\text { activities }\end{array}$ & 27 & $9.06 \pm 1.30$ & $4.85 \pm 3.22$ & $4.21 \pm 3.24$ & $6.75^{\dagger} 26$ \\
\hline $\begin{array}{l}\text { Combined pain } \\
\text { severity }\end{array}$ & 27 & $9.19 \pm 1.03$ & $5.09 \pm 3.27$ & $4.09 \pm 3.00$ & $7.09^{\dagger} 26$ \\
\hline Pain frequency & 26 & $4.23 \pm 1.14$ & $3.07 \pm 1.32$ & $1.15 \pm 1.73$ & $3.38^{\dagger} 25$ \\
\hline $\begin{array}{l}\text { Emotional problems } \\
\text { with social activities }\end{array}$ & 27 & $3.85 \pm 1.32$ & $2.92 \pm 1.38$ & $0.92 \pm 1.17$ & $4.09^{\dagger} 26$ \\
\hline
\end{tabular}

${ }^{*} M e a n \pm S D,{ }^{\dagger} P<0.05$. Note: The values represent significance decreases in all means post-therapy which, in turn, reflects a decrease in the level of difficulty in functional status, pain severity and frequency, and in the limitation of participation in social activities experienced by clients. df Degrees of freedom

and after therapy on a scale ranging from 1 (never) to 5 (always). Table 1 shows mean \pm SD pretherapy, post-therapy and change scores. The results indicate a significant decrease in both the amount and frequency of pain following therapy.

\section{Functional status}

Participants were asked to rate their functional status before and after therapy based on two broad groups of activities: specific and regular. Each group consisted of five activities. Specific activities included turning a doorknob, cutting meat using a knife, fastening buttons, carrying a heavy object ( $5 \mathrm{~kg}$ or more) and using bathroom tissue. Regular activities included personal care, household chores, having meals, job-related activities and recreational activities. Clients were asked to rate the level of difficulty that they had experienced in performing each activity with the affected hand on a scale of 0 (no difficulty) to 10 (unable to do). The sum of each set of activities was calculated separately and the average pretherapy and posttherapy scores were compared as shown in Table 1.

The significant decreases in the means of the post-therapy ratings for both specific and regular activities indicate a decrease in the level of difficulty experienced by clients in performing these activities, which, in turn, indicates improvement in the clients' functional status.

\section{Emotional status}

Participants were asked to report, in a series of yes or no questions, whether they had felt emotional disturbances associated with their CRPS. Only 25 participants answered this question, of which $53.60 \%$ indicated that they had experienced emotional disturbances associated with CRPS before or at the beginning of their therapy. In contrast, only $35.70 \%$ reported such disturbances following treatment. Those who indicated that they were experiencing emotional disturbances following therapy were asked to compare their post-therapy emotional status with their pretherapy emotional status using four categories. The majority of respondents did not answer this question. Of those who did, only 3.60\% indicated that they felt the same, while $17.80 \%$ indicated that they were coping well, $10.70 \%$ that they felt worse and $3.60 \%$ that they felt better.

Clients were also asked to rate, on a scale ranging from 1 (not at all) to 5 (extremely), the extent to which their hand condition or emotional problems interfered with normal social activities with family, friends or neighbours before and after therapy. The change scores indicate that the limitations experienced by the clients in participating in social activities decreased after they received therapy. Table 1 presents the differences in the two means and the change scores.

\section{Treatment and overall satisfaction}

Each client received a different combination of treatment modalities tailored specifically to that client's individual needs, taking into account the stage in the progression of CRPS in the affected hand, the current level of pain and the degree of impairment in hand functionality. Participants listed the various kinds of treatment that they had received and then rated the effectiveness of each on an 11-point Likert scale, ranging from 0 (not at all) to 10 (extremely). All indicated that they received proper education and hand exercises for managing their CRPS. Pain medications had been administered to $96.40 \%$ of participants. Splints $(82.10 \%)$ and nerve block injections $(71.40 \%)$ had been the next most prescribed treatment modalities. The continuous passive motion machine had been used in $53.60 \%$ of the cases, while $14.30 \%$ of participants reported the use of other treatments such as electrical stimulation and fluidotherapy. On average, the scores for the effectiveness of the different combination of treatment modalities (mean score 6.24 \pm 2.50 ) suggest a clinically effective outcome.

Clients were asked to rate their overall level of satisfaction with the treatment that they had received based on its positive effect on their functional status, pain severity and frequency, and emotional status. The clients' satisfaction level ranged between 2 and 5 on a scale ranging from 1 (not at all) to 5 (extremely). The mean score $(4.59 \pm 0.79 ; n=27)$ suggests that satisfaction with the therapy or treatment received was remarkably high.

\section{DISCUSSION}

The findings of the present study indicate that the participants were generally satisfied with the therapy that they had received for CRPS. In terms of the clients' functional, emotional and pain status, all post-therapy scores indicated a change that is significant not only clinically but also statistically. The high satisfaction rate is attributable to a treatment regimen that is founded on the principle of close collaboration among surgeons, therapists and pain clinic specialists, with the specific needs of each client determining the nature of the treatment regimen. It must be concluded that this holistic approach in treating CRPS is fundamental to the favourable rating given by the participants in the present survey. At our facility, the psychological and emotional status is considered part of the treatment plan. Thus, the therapist plays a major role in motivating the clients by assisting them in overcoming their symptoms and focusing on their treatment program.

One drawback to the study is that some respondents did not answer all of the questions, and this reduced the already small sample size. In addition, some participants had only recently recovered from CRPS, whereas others had recovered as much as seven years earlier. In a study conducted to investigate how the subjective properties of autobiographical memories change over time, Friedman and deWinstanley (37) concluded that memory of an event declines rapidly over the first 12 weeks following that event. In light of this finding, it can be suggested that the method used in the present study would be 
most effective if conducted in two stages: the pretherapy stage and the post-therapy stage. The pretherapy evaluation should be done when the client first presents with the problem, seeking treatment (38). The post-therapy evaluation should be done within 12 weeks of completing the therapy program (39). In addition, baseline measurements of range of motion and grip and pinch strengths should be taken in the pretherapy evaluation and once again in the post-therapy evaluation to provide an objective determination of the improvements in hand functionality (38). These modifications would enhance the validity of the evaluation process (38). In addition, several replications of the survey would enlarge the sample size and enhance the reliability of the results.

Another weakness of this study was the mail-out/mail-in method of conducting the survey. In the present case, the researchers were faced with the question of how long to wait before assuming that a particular prospective participant who had not yet responded was, in fact, not going to respond at all. In addition, the researchers were somewhat frustrated by the lack of flexibility and the inability to probe responses for further information or clarification. Furthermore, it was believed that despite the pilot testing and the refining of the questionnaire, some respondents may have had difficulty understanding the questions, especially those with lower educational and literacy levels, or those for whom English was not a first language. Apart from these difficulties that the researchers faced with the mailout/mail-in method, it is well recognized among researchers that this method has a built-in bias in that it automatically limits participants to those members of the population who have some interest in using their personal experience to benefit others, and eliminates those who may be too busy or simply indifferent, but whose experiences may nevertheless be valuable to the study (28). Therefore, it is recommended that the survey be conducted face-to-face with each client (if consent is obtained) when he or she is first diagnosed with CRPS, and that the same procedure be followed after the course of hand therapy is completed. Based on the limitations of our study, outcome measure forms have been proposed to collect data on pre and post treatment status of the CRPS clients (Appendixes 1 and 2).

\section{CONCLUSION}

CRPS is one of the most challenging pain syndromes for the hand therapist to treat. The present study sought to determine client satisfaction with a given hand therapy for CRPS. The results show that clients were generally satisfied with the course of therapy that they had received. The findings of the present study confirm the hypothesis that the treatment regimen used at St Joseph's Health Care London Hand and Upper Limb Centre, London, Ontario, to treat clients with CRPS is highly effective in achieving the desired outcomes. Researchers and clinicians will benefit from using the questionnaire developed for this study as an outcome measure to evaluate the effectiveness of treatment programs based on client satisfaction ratings. Further investigations into whether hand dominance and employment status are related to overall client satisfaction with the therapy received will deepen our understanding of the issues that need to be addressed to raise client satisfaction to the maximum.

\section{APPENDIX 1}

\section{Patient Rated Complex Regional Pain Syndrome (CRPS) Evaluation Satisfaction of the Effectiveness of Therapy Intervention}

\section{PRE-TREATMENT STATUS}

Age: $\_$Gender: $\square$ Male $\square$ Female

What is your current occupation?

What is your current employment status? (Mark one box)

Full-time $\quad \square$ Part-time $\quad \square$ Unable to work because of hand condition

\begin{tabular}{ll}
\hline Which hand do you write with (dominant hand)? & $\square$ Right $\square$ Left \\
Which hand/arm was involved? & $\square$ Right $\square$ Left \\
\hline
\end{tabular}

Was your hand problem the result of an injury?

If Yes $\bullet$ What was the injury?

- When did the injury happen?

If No • What caused your problem?

- When did the problem start?

How soon following your problem were you diagnosed with (Complex Regional Pain Syndrome CRPS)? (Mark one box)
Within 3 weeks
4 - 6 weeks
3 months
6 months
Over 6 months 


\section{APPENDIX 1 - CONTINUED}

What is the amount of pain do you experience now? (Circle a number)

\begin{tabular}{|l|lllllllllll|}
\hline & \multicolumn{1}{|l}{ none } & \multicolumn{1}{c|}{ >>> worst } \\
\hline At rest & 0 & 1 & 2 & 3 & 4 & 5 & 6 & 7 & 8 & 9 & 10 \\
\hline Lifting heavy objects & 0 & 1 & 2 & 3 & 4 & 5 & 6 & 7 & 8 & 9 & 10 \\
\hline Doing repeated wrist-hand movements & 0 & 1 & 2 & 3 & 4 & 5 & 6 & 7 & 8 & 9 & 10 \\
\hline At night & 0 & 1 & 2 & 3 & 4 & 5 & 6 & 7 & 8 & 9 & 10 \\
\hline At its worst & 0 & 1 & 2 & 3 & 4 & 5 & 6 & 7 & 8 & 9 & 10 \\
\hline
\end{tabular}

How often do you experience pain now? (Circle a number)

\begin{tabular}{|c|c|c|c|c|}
\hline 1 & 2 & 3 & 4 & 5 \\
\hline Never & \multicolumn{4}{|c|}{ Always } \\
\hline
\end{tabular}

How much difficulty do you experience in doing the following activities with your affected hand?

(Circle a number)

\begin{tabular}{|c|c|c|c|c|c|c|c|c|c|c|c|}
\hline A. SPECIFIC ACTIVITIES: & \multicolumn{8}{|c|}{ no difficulty $<<<$} & \multicolumn{3}{|c|}{ >>> unable to do } \\
\hline Turning a doorknob & 0 & 1 & 2 & 3 & 4 & 5 & 6 & 7 & 8 & 9 & 10 \\
\hline Cutting meat using a knife & 0 & 1 & 2 & 3 & 4 & 5 & 6 & 7 & 8 & 9 & 10 \\
\hline Fastening buttons & 0 & 1 & 2 & 3 & 4 & 5 & 6 & 7 & 8 & 9 & 10 \\
\hline Carrying a heavy object (10 lbs. or more) & 0 & 1 & 2 & 3 & 4 & 5 & 6 & 7 & 8 & 9 & 10 \\
\hline Using bathroom tissue & 0 & 1 & 2 & 3 & 4 & 5 & 6 & 7 & 8 & 9 & 10 \\
\hline
\end{tabular}

\begin{tabular}{|c|c|c|c|c|c|c|c|c|c|c|c|}
\hline B. REGULAR ACTIVITIES: & \multicolumn{8}{|c|}{ no difficulty $\ll<<$} & \multicolumn{3}{|c|}{ >>> unable to do } \\
\hline Personal care (dressing, washing, brushing teeth, etc.) & 0 & 1 & 2 & 3 & 4 & 5 & 6 & 7 & 8 & 9 & 10 \\
\hline Household chores (cleaning, cooking, laundry, etc.) & 0 & 1 & 2 & 3 & 4 & 5 & 6 & 7 & 8 & 9 & 10 \\
\hline Having meals & 0 & 1 & 2 & 3 & 4 & 5 & 6 & 7 & 8 & 9 & 10 \\
\hline Job-related activities/work & 0 & 1 & 2 & 3 & 4 & 5 & 6 & 7 & 8 & 9 & 10 \\
\hline Recreational activities & 0 & 1 & 2 & 3 & 4 & 5 & 6 & 7 & 8 & 9 & 10 \\
\hline
\end{tabular}

Do you have any emotional disturbances as a result of CRPS now?

$\square$ Yes $\quad \square$ No

To what extent has your hand condition or (emotional problems as a result of your hand condition) interfered with your normal social activities with family, friends, neighbours or groups now? (Mark one box)

Not at all $\square$ Slightly

Moderately

Quite a bit

Extremely

\begin{tabular}{|c|c|c|c|c|c|c|c|c|}
\hline & ROM & MCP & PIP & DIP & & & AROM & PROM \\
\hline \multirow[t]{2}{*}{ Index } & Active & / & $/$ & / & Wrist & Ext/Flex & / & / \\
\hline & Passive & / & / & / & & RD/UD & / & / \\
\hline \multirow[t]{2}{*}{ Middle } & Active & / & / & / & & Pro/Sup & / & / \\
\hline & Passive & / & / & / & Elbow & Ext/Flex & / & / \\
\hline \multirow[t]{2}{*}{ Ring } & Active & / & / & / & Shoulder & Ext/Flex & / & / \\
\hline & Passive & / & / & / & & Abduction & / & / \\
\hline \multirow[t]{3}{*}{ Little } & Active & / & $/$ & / & & Int. Rotation & / & / \\
\hline & Passive & / & / & / & & Ext. Rotation & / & / \\
\hline & ROM & MP & IP & & Opposition & & & \\
\hline \multirow[t]{2}{*}{ Thumb } & Active & I & / & & & & & \\
\hline & Passive & / & / & & & & & \\
\hline Strength & $\begin{array}{l}\text { Grip: } \\
\text { (R) } \\
\text { (L) } \\
\end{array}$ & & $\begin{array}{l}\text { Key } \\
\text { (R) } \\
\text { (L) } \\
\end{array}$ & & $\begin{array}{l}\text { 2-point: } \\
\text { (R) } \\
\text { (L) }\end{array}$ & $\begin{array}{l}\text { 3-point: } \\
\text { (R) } \\
\text { (L) } \\
\end{array}$ & & \\
\hline
\end{tabular}




\section{APPENDIX 2}

\section{Patient Rated Complex Regional Pain Syndrome (CRPS) Evaluation Satisfaction of the Effectiveness of Therapy Intervention}

\section{POST-TREATMENT STATUS}

Which of the following treatments did you receive for your condition? (Select all that apply)

\begin{tabular}{|l|l|lllllllllll|}
\hline TREATMENT & & \multicolumn{8}{|l|}{ How helpful was the treatment? } \\
\hline & & not at all $<<<$ & & & \multicolumn{7}{c|}{ >> extremel } \\
\hline$\square$ Splint & 0 & 1 & 2 & 3 & 4 & 5 & 6 & 7 & 8 & 9 & 10 \\
\hline$\square$ Cast & 0 & 1 & 2 & 3 & 4 & 5 & 6 & 7 & 8 & 9 & 10 \\
\hline$\square$ Surgery for CRPS & 0 & 1 & 2 & 3 & 4 & 5 & 6 & 7 & 8 & 9 & 10 \\
\hline$\square$ Therapy/Exercise/Activity & & 0 & 1 & 2 & 3 & 4 & 5 & 6 & 7 & 8 & 9 & 10 \\
\hline$\square$ Pain Medications & 0 & 1 & 2 & 3 & 4 & 5 & 6 & 7 & 8 & 9 & 10 \\
\hline$\square$ Injections/Blocks for Pain & 0 & 1 & 2 & 3 & 4 & 5 & 6 & 7 & 8 & 9 & 10 \\
\hline $\begin{array}{l}\text { Continuous Passive Motion } \\
\text { Machine(CPM) }\end{array}$ & 0 & 1 & 2 & 3 & 4 & 5 & 6 & 7 & 8 & 9 & 10 \\
\hline$\square$ Other & & & & & & & & & & & \\
\hline
\end{tabular}

How much difficulty do you experience in doing the following activities with your affected hand now? (Circle a number)

\begin{tabular}{|c|c|c|c|c|c|c|c|c|c|c|c|}
\hline A. SPECIFIC ACTIVITIES: & \multicolumn{8}{|c|}{ no difficulty $\ll<<$} & \multicolumn{3}{|c|}{ >>> unable to do } \\
\hline Turning a doorknob & 0 & 1 & 2 & 3 & 4 & 5 & 6 & 7 & 8 & 9 & 10 \\
\hline Cutting meat using a knife & 0 & 1 & 2 & 3 & 4 & 5 & 6 & 7 & 8 & 9 & 10 \\
\hline Fastening buttons & 0 & 1 & 2 & 3 & 4 & 5 & 6 & 7 & 8 & 9 & 10 \\
\hline Carrying a heavy object (10 lbs. or more) & 0 & 1 & 2 & 3 & 4 & 5 & 6 & 7 & 8 & 9 & 10 \\
\hline Using bathroom tissue & 0 & 1 & 2 & 3 & 4 & 5 & 6 & 7 & 8 & 9 & 10 \\
\hline B. REGULAR ACTIVITIES: & & & & & & & & & & & \\
\hline Personal care (dressing, washing, etc.) & 0 & 1 & 2 & 3 & 4 & 5 & 6 & 7 & 8 & 9 & 10 \\
\hline Household chores (cleaning, cooking, laundry, etc.) & 0 & 1 & 2 & 3 & 4 & 5 & 6 & 7 & 8 & 9 & 10 \\
\hline Having meals & 0 & 1 & 2 & 3 & 4 & 5 & 6 & 7 & 8 & 9 & 10 \\
\hline Job-related activities/work & 0 & 1 & 2 & 3 & 4 & 5 & 6 & 7 & 8 & 9 & 10 \\
\hline Recreational activities & 0 & 1 & 2 & 3 & 4 & 5 & 6 & 7 & 8 & 9 & 10 \\
\hline
\end{tabular}

What is the amount of pain do you experience now? (Circle a number)

\begin{tabular}{|l|lllllllllll|}
\hline & none $<<<$ & \multicolumn{1}{c|}{ >> worst } \\
\hline At rest & 0 & 1 & 2 & 3 & 4 & 5 & 6 & 7 & 8 & 9 & 10 \\
\hline Lifting heavy objects & 0 & 1 & 2 & 3 & 4 & 5 & 6 & 7 & 8 & 9 & 10 \\
\hline Doing repeated wrist-hand movements & 0 & 1 & 2 & 3 & 4 & 5 & 6 & 7 & 8 & 9 & 10 \\
\hline At night & 0 & 1 & 2 & 3 & 4 & 5 & 6 & 7 & 8 & 9 & 10 \\
\hline At its worst & 0 & 1 & 2 & 3 & 4 & 5 & 6 & 7 & 8 & 9 & 10 \\
\hline
\end{tabular}

How often do you experience pain now? (Circle a number)

\begin{tabular}{|c|c|c|c|c|}
\hline 1 & 2 & 3 & 4 & 5 \\
\hline Never
\end{tabular}




\section{APPENDIX 2 - CONTINUED}

Do you have any emotional disturbances as a result of CRPS now?
$\square$ Yes
$\square$ No

If yes, how is your emotional status now compared to before or at the beginning of treatment? (Mark one box)
$\square$ The same
Better
$\square$ Worse
Coping well

To what extent has your hand condition or (emotional problems as a result of your hand condition) interfered with your normal social activities with family, friends, neighbours or groups now?

(Mark one box)

$\square$ Not at all $\square$ Slightly $\square$ Moderately

Have you changed your job because of your hand condition?

$\square$ Quite a bit

$\square$ Extremely

If Yes • What was your previous occupation?

- What was your previous employment status? (Mark one box)

$\square$ Full-time $\quad \square$ Part-time $\quad \square$ Unable to work because of hand condition

If No • How has your ability to work been affected by your hand condition? (Mark all that apply)

$\square$ Not at all $\square$ Working fewer hours $\square$ Workin modified duties

How satisfied are you with the treatment you received? (Circle a number)

\begin{tabular}{|c|c|c|c|c|}
\hline 1 & 2 & 3 & 4 & 5 \\
\hline Not at all
\end{tabular}

\begin{tabular}{|c|c|c|c|c|c|c|c|c|c|}
\hline & ROM & MCP & PIP & DIP & & & & AROM & PROM \\
\hline Index & Active & $/$ & $/$ & $/$ & Wrist & Ext/Flex & $/$ & $/$ \\
\hline & Passive & $/$ & $/$ & $/$ & & RD/UD & $/$ & $/$ \\
\hline Middle & Active & $/$ & $/$ & $/$ & & Pro/Sup & $/$ & $/$ \\
\hline & Passive & $/$ & $/$ & $/$ & Elbow & Ext/Flex & $/$ & $/$ \\
\hline Ring & Active & $/$ & $/$ & $/$ & Shoulder & Ext/Flex & $/$ & $/$ \\
\hline & Passive & $/$ & $/$ & $/$ & & Abduction & $/$ & $/$ \\
\hline Little & Active & $/$ & $/$ & $/$ & & Int. Rotation & $/$ & $/$ \\
\hline & Passive & $/$ & $/$ & $/$ & & Ext. Rotation & $/$ & $/$ \\
\hline & ROM & MP & IP & & Opposition & & & \\
\hline Thumb & Active & $/$ & $/$ & & & & & \\
\hline & Passive & $/$ & $/$ & & & & & \\
\hline
\end{tabular}

\begin{tabular}{|l|l|l|l|l|}
\hline Strength & Grip: & Key: & 2-point: & 3-point: \\
& $(\mathrm{R})$ & $(\mathrm{R})$ & $(\mathrm{R})$ & $(\mathrm{R})$ \\
& $(\mathrm{L})$ & $(\mathrm{L})$ & $(\mathrm{L})$ & $(\mathrm{L})$ \\
\hline
\end{tabular}




\section{REFERENCES}

1. Stanton-Hicks M, Jänig W, Hassenbusch S, Haddox JD, Boas R, Wilson P. Reflex sympathetic dystrophy: Changing concepts and taxonomy. Pain 1995;63:127-33.

2. Vacariu G. Complex regional pain syndrome. Disabil Rehabil 2002;24:435-42.

3. Forderreuther S, Sailer U, Straubem A. Impaired self-perception of the hand in complex regional pain syndrome (CRPS). Pain 2004;110:756-61.

4. Rommel O, Gehling M, Dertwinkel R, et al. Hemisensory impairment in patients with complex regional pain syndrome. Pain 1999;80:95-101.

5. Allen G, Galar BS, Schwartz L. Epidemiology of CRPS: A retrospective chart review of 134 patients. Pain 1999;80:539-44.

6. Moots PL, Kandula P. Principles of pain management. In: Bradley WG, Daroff RB, Fenichel GM, Jankovic J, eds. Neurology in Clinical Practice: Principles of Diagnosis and Management, 4th edn. Philadelphia: Elsevier, 2004;1:921-40.

7. Kozin F. Reflex sympathetic dystrophy syndrome: A review. Clin Exp Rheumatol 1992;10:401-9.

8. An HS, Hawthorne KB, Jackson WT. Reflex sympathetic dystrophy and cigarette smoking. J Hand Surg [Am] 1988;13:458-60.

9. Ciccone DS, Bandilla EB Wu W. Psychological dysfunction in patients with reflex sympathetic dystrophy. Pain 1997;71:323-33.

10. Geertzen JH, Dijkstra PU, Groothoff JW, ten Duis HJ, Eisma WH. Reflex sympathetic dystrophy of the upper extremity - A 5.5-year follow-up. Part I. Impairments and perceived disability. Acta Orthop Scand Suppl 1998;279:12-8.

11. Geertzen JH, Dijkstra PU, Groothoff JW, ten Duis HJ, Eisma WH. Reflex sympathetic dystrophy of the upper extremity - A 5.5-year follow-up. Part II. Social life events, general health and changes in occupation. Acta Orthop Scand Suppl 1998;279:19-23.

12. Geertzen JH, Dijkstra PU, van Sonderen EL, Groothoff JW, ten Duis HJ, Eisma WH. Relationship between impairments, disability and handicap in reflex sympathetic dystrophy patients: A long-term follow-up study. Clin Rehabil 1998;12:402-12.

13. Kemler MA, Furnee CA. The impact of chronic pain on life in the household. J Pain Symptom Manage 2002;23:433-41.

14. Muir JM, Vernon H. Complex regional pain syndrome and chiropractic. J Manipulative Physiol Ther 2000;23:490-7.

15. Fialka V, Korpan M, Saradeth T, et al. Autogenic training for reflex sympathetic dystrophy: A pilot study. Complement Ther Med 1996;4:103-5.

16. Wesdock KA, Stanton RP, Singsen BH. Reflex sympathetic dystrophy in children: A physical therapy approach. Arthritis Care Res 1991;4:32-8.

17. Lee BH, Scharff L, Sethna NF. Physical therapy and cognitivebehavioural treatment for complex regional pain syndromes. J Pediatr 2002;141:135-40.

18. Lankford LL. Reflex sympathetic dystrophy. In: Hunter JM, Mackin EJ, Callahan AD, eds. Rehabilitation of the Hand: Surgery and Therapy, 4th edn. St Louis: Mosby, 1995:779-815.

19. Stanton Hicks M, Baron R, Boas R, et al. Complex regional pain syndrome: Guidelines for therapy. Clin J Pain 1998;14:155-66.

20. Zyluk A. The sequelae of reflex sympathetic dystrophy. J Hand Surg [Br] 2001;26:151-4.

21. Halbertsma J, Heerkens YF, Hirs WM, de Kleijn-de Vrankrijker MW, Dorine Van Ravenseberg CD, Napel HT. Towards a new
ICIDH. International Classification of Impairments, Disabilities and Handicaps. Disabil Rehabil 2000;22:144-156.

22. Simeonsson RJ, Lollar D, Hollowell J, Adams M. Revision of the International Classification of Impairments, Disabilities, and Handicaps: Developmental issues. J Clin Epidemiol 2000;53:113-24.

23. Schasfoort FC, Bussmann JB, Stam HJ. Impairments and activity limitations in subjects with chronic upper-limb complex regional pain syndrome type I. Arch Phys Med Rehabil 2004;85:557-66.

24. Phillips ME, Katz JA, Harden RN. The use of nerve blocks in conjunction with occupational therapy for complex regional pain syndrome type I. Am J Occup Ther 2000;54:544-9.

25. Walsh MT, Muntzer E. Therapist's management of complex regional pain syndrome (Reflex sympathetic dystrophy). In: Mackin EJ, Callahan AD, Skirven TM, Schneider LH, Osterman AL, eds. Rehabilitation of the Hand and Upper Extremity, 5th edn. St Louis: Mosby, 2002:1707-24.

26. Stanton-Hicks MD, Burton AW, Bruehl SP, et al. An updated interdisciplinary clinical pathway for CRPS: Report of an expert panel. Pain Pract 2002;2:1-16.

27. Gray GA, Guppy N. Successful Surveys: Research Methods and Practice. Toronto: Harcourt Brace \& Co, 1999.

28. Dillman DA. Mail and Telephone Surveys: The Total Design Method. New York: John Wiley \& Sons, 1978.

29. MacDermid JC. Development of a scale for patient rating of wrist pain and disability. J Hand Ther 1996;9:178-83.

30. MacDermid JC, Turgeon T, Richards RS, Beadle M, Roth JH. Patient rating of wrist pain and disability: A reliable and valid measurement tool. J Orthop Trauma 1998;12:577-86.

31. Ware JE, Kosinski M, Keller SD. SF-36 Physical and Mental Health Summary Scales: A User's Manual. Boston: The Health Institute, New England Medical Centre, 1994.

32. Ware JE, Snow KS, Kosinski M, Gandek B. SF-36 Health Survey Manual and Interpretation Guide. Boston: The Health Institute, New England Medical Centre, 1993.

33. Hudak PL, Amadio PC, Bombardier C. Development of an upper extremity outcome measure: The DASH (disabilities of the arm, shoulder and hand). The Upper Extremity Collaborative Group (UECG). Am J Ind Med 1996;29:602-8. (Erratum in 1996;30:372).

34. Beaton DE, Katz JN, Fossel AH, Wright JG, Tarasuk V, Bombardier C. Measuring the whole or parts? Validity, reliability and responsiveness of the Disabilities of the Arm, Shoulder and Hand Outcome Measure in different regions of the upper extremity. J Hand Ther 2001;14:128-42.

35. Statistical Package for the Social Sciences (SPSS) for Windows, Rel. 11.0.1.(2001). Chicago: SPSS Inc; 2001.

36. D'Agostino RB Sr, Sullivan LM, Beiser AS. Introductory Applied Biostatistics. Canada: Thomson Nelson, 2004.

37. Friedman WJ, deWinstanley PA. Changes in the subject properties of autobiographical memories with the passage of time. Memory 1998;6:367-81.

38. Schneider LH. Impairment evaluation. In: Mackin EJ, Callahan AD, Skirven TM, Schneider LH, Osterman AL, eds. Rehabilitation of the Hand and Upper Extremity, 5th edn. St Louis: Mosby, 2002:279-307.

39. MacDermid JC. Outcome measurement in the upper extremity. In: Mackin EJ, Callahan AD, Skirven TM, Schneider LH, Osterman AL, eds. Rehabilitation of the Hand and Upper Extremity, 5th edn. St Louis: Mosby, 2002:285-96. 